\title{
Analysis, Design and Implementation of Multi Agent System in Web Data Mining
}

\author{
Shakti Kundu and Madan Lal Garg \\ Department of Computer Science \& Engineering, \\ DIT University, Dehradun - 248009, Uttarakhand, India \\ shaktikundu@gmail.com,mlgarg2000@yahoo.com
}

\begin{abstract}
When users access any online website, web access logs are generated on the server. Web log analyzer helps us to analyze user behavior that contain information such as user name, IP address, number of hits, files, visit, bytes transferred and uniform resource locator that referred. It is very important to have web log analyzer tools which help us in knowing the emerging trends of e-commerce and user with an approach of web analytics. Each and every tool is having some feature and limitation. Through comparative study it gives direction to select which analyzer tool to be used in frequent manner or in a specific circumstance to better understand the behavior of user. Agents refer to the calculating entities with characteristics such as independence, duration and acting as an agent under certain environment. Agents are significant because they permit various software components the ability to exchange and use information in web content retrieval. Agents require a common agent communication language to describe and process agent's requests. Also user requirements such as getting accurate information in a prompt manner are not getting fulfilled as per their expectations. With JADE and Multi Agent System, it becomes easier to implement Agents and can effectively improve the intelligence of the system.
\end{abstract}

Keywords: Agents, Programming, Software, Web Data Mining

\section{Introduction}

Web data mining or Data mining in e-commerce is a rapidly growing field, the development of which is driven by the explosive growth of online information and the economic need to provide personalized products and services. Due to extensive growth of the web, websites are playing an important act in delivering the relevant information to the users. Web data mining architecture is an important aspect to discover hidden and interesting information. When volume of web data is in growing phase then web traffic mining becomes challenging. The web data analysis will eliminate the irrelevant rules or patterns that were generated. They tend to extract the interesting rules or patterns from the output of pattern discovery and pattern analysis process. An intelligent perspective of web data mining and analysis has been discussed to face the challenge of huge web data. Although data mining applications have been around for several decades, e-commerce provides new issues and new challenges for the field.

E-commerce is an ideal domain for data mining. Compared with traditional offline business, it deals with large quantities of data that keep growing at exponential speed. The enormous amounts of data generated from a web site, for example, could provide meaningful insights into:

- What types of visitors are likely to make purchases?

Received (August 21, 2017), Review Result (November 29, 2017), Accepted (November 30, 2017) 
- What are the most typical navigation patterns?

- What pages are most / least visited?

Web mining systems are able to collect data which otherwise are difficult or costly to access and are able to keep track of customer actions in virtual stores, that is, What articles they look at?; How they browse a catalog?; What kind of items they put into their shopping cart?.

Intelligent agents are software entities that carry out some set of operations on behalf of a user or another program, with some degree of independence or autonomy and in doing so, employ some knowledge or representation of the user's goals or desires [1]. Intelligent agent may be defined as computer program that helps a user with routine computer tasks. Other names of intelligent agent are Software Agents, Intelligent Software Robots, Softbots, Bots.

Intelligent agent may be defined as computer program that helps a user with routine computer tasks. Other names of intelligent agent are Software Agents, Intelligent Software Robots, Softbots, Bots.

Quality of data is another feature that makes e-commerce especially suitable for data mining. Collecting data electronically significantly reduces the noise associated with manual data entry and processing. Noisy and corrupt data can hide some important patterns which introduce inconsistencies or lead to misleading interpretations [2].

An important advantage of e-commerce data mining or web data mining is the possibility of conducting controlled experiments and measuring their effects on business goals. Direct marketing, for example, can target particular groups, and the results can be data mined for predictive behavior modeling of consumers [2].

Though the existing data mining systems have advantages of their own, yet they are not so perfect enough concerning the intelligence aspect, and still need to be perfected. The agents play high quality intelligence role in the field of web data mining. The combination of the Multi Agent System can realize the whole intellectuality of mining process [3].

\section{Preliminaries}

An agent is a computer system, situated in some environment that is capable of flexible autonomous action in order to meet its design objectives. It is well suited for developing e-commerce systems. The relationship between agent and e-commerce can be found easily from agent's characteristics. From the end-user perspective, an agent is a program that assists people and acts on their behalf [4].

Multi Agent system is a powerful paradigm in nowadays distributed systems. In Multi Agent environments, Agents often need to interact in order to achieve their objectives or improve their performance. If agents are to negotiate automatically with one another they must share a negotiation mechanism [5].

Multi Agent System (MAS) is a system composed of many agents, and generally these agents exchange information through network infrastructure. In MAS, the ability of an individual agent is limited, but Multi Agent System can finish a lot of complicated tasks through cooperation [6].

Data mining agent is a software program built for the primary purpose of finding the information efficiently that operates on a data store. This type of agent is able to detect both major trend changes and new trends [7].

In e-commerce, logs cluster analysis is a good mining method. The cluster objects include customer groups and web pages. The cluster of customer groups plays an important role in providing personalized services in e-commerce website. In order to cluster customer groups, we must describe their browser action [8].

The daily records of a server can be expressed in the following form: $\mathrm{L}=$ (IP, User ID, URL, Start time, Finish time), where IP, User ID, URL, Start time, Finish time stand for 
the customer's IP address, customer ID, the URL hit by customer, landing time and leaving time respectively [4].

Web usage mining is the technique which considers either General Access Patterns or Customized Access Patterns. General Access Patterns include general access log data whereas Customized Access Patterns include usage activities in relation to their visit and interaction with the website. It looks for analysis of web clicks and web pages visited during a given term in an ordered approach [9].

The information related to web pages visit is stored in the manner of log files on internet servers. Web mining with the help of log analyzer recognizes the earlier unidentified and probably interesting sequence of related information. It is specified as operating log files to improve the website through data mining techniques. Each click of the mouse corresponds to a web page request; the sequence of clicks corresponds to such sequence links [9].

The aim of web mining is to spontaneously recognize and examine prototype of various click stream. It also focuses in knowing the associated gathered data as an outcome of user interface with increasingly web sites. To evaluate user behavior, profiles of end users communicating with the online site are traced, modeled and analyzed in order to improve services [10].

Web usage mining which is one of the data mining technique helps in determining usage patterns from Web data. This activity is proceeded to know and improve the requirements of web applications. It comprise of two stages, namely discovery and analysis of prototype [11].

\section{Problem Description}

Gaps found through study of existing literature where many researchers have provided different techniques for web data mining, such as:

1) R. Cooley et al. highlighted WEBMINER system [12] which works on SQL-like query mechanism for extracting the discovered knowledge. However, the expressiveness of this language is restricted by the input parameters acceptable by the miner (Current miners do not support generic specifications on the structure of patterns to be discovered e.g. page revisit, cycles etc.)

2) Sandeep Neeli et al. [13] proposed automated data mining using Perl script from web servers. The proposed search tool prepared on the platform of Perl / CGI script which is an outdated approach followed by the researcher in the past.

3) Liren Chen et al. [10] proposed WebMate, a personal software agent for browsing and searching but having limited scope of exploring.

4) Robert Armstrong et al. [14] presented the design and implementation of an agent called WebWatcher that is intended to assist users both by interactively advising them as they traverse web links in search of information, and by searching autonomously on their behalf.

5) Henry Liberman [16, 17] introduced an agent Letizia that tracks the user's browsing behavior and tries to anticipate what items may be of interest to the user.

6) Henry Liberman et al. [18] proposed reconnaissance agents with two examples: Letizia and Powerscout. The main deifference is Letizia uses local reconnaissance (searching the neighborhood of current page), while Powerscout uses global reconnaissance (making use of traditional search engine to search the Web in general).

7) WebSIFT (Website Information Filter) [19] is designed to perform web usage mining from server logs. The preprocessing algorithms include identifying users, server sessions, and identifying cached page references through the use of the referrer 
field. It identifies interesting information and frequent item sets from mining usage data.

8) Most of the web log analyzer tools are used for pattern discovery and patter analysis. Using various web analyzer tools, it is possible to detect the number of accesses to the server and URL of users. Such tools provide knowledge about number of hits, files, page visited. However, such tools are having certain criticism. For instance, Webalizer [20] which is one of the popular web log analyzer tool but it is having one major limitation. It cannot differentiate between the human user visit and robot visit.

\section{Methodologies and Contributions}

The methodologies and main contributions are as follows:

- Comparative study of 10 various web $\log$ analyzer tools with its features and limitation.

- An intelligent perspective of web data mining and analysis have been done with the help of web data analysis and graphing workspace tool i.e. Origin Pro 8

- Implementations of software agents via Java Application Development Environment for e-commerce applications have been highlighted.

- Created software agents to improve the efficiency of web data mining system.

- Evaluation of the proposed model as multi agent system in which agents are communicating with other agents to provide accurate, relevant and customized information.

- The proposed system i.e. WEBMINTEL (Web Mining Intelligent Agents System) is an associated multi agent system in which an agent has the feasibility to select three analyzing offers: accept, reject and add to cart, and also to evaluate the cases using the knowledge base.

- A framework of automated analyzing WEBMINTEL system with multi software agents have been developed through JSP and JDBC modules. This approach seems to be intelligent due to the usage of latest tools and methodologies. The outcome of proposed system is positive and efficient in comparison to the outdated directions which had been followed by many researchers in the past such as Perl and SQL like query mechanism.

\section{Research Findings}

\subsection{Web Log Analyzer Tools: A Comparative Study to Analyze User Behavior}

The comparison of 10 web log analyzer tools had been highlighted in Table 1 with features and criticism. The web log analyzer tools, namely, Webalizer, Piwik, Open Web Analytics, Deep Log Analyzer, Fire Stats, Go Access, Web Forensik, AW Log Analyzer, Web Log Expert and Google Analytics have been compared based on the characteristics such as vendor, type, current version, installation, log file formats, language available in, operation system and some criticism. 
Table 1. Comparison of Web Log Analyzer Tools

\begin{tabular}{|c|c|c|c|c|c|c|c|c|c|c|}
\hline $\begin{array}{c}\text { WLA Tools } \\
\text { Features }\end{array}$ & Webalizer & Piwik & $\begin{array}{c}\text { Open } \\
\text { Web } \\
\text { Analytics }\end{array}$ & $\begin{array}{c}\text { Deep } \\
\text { Log } \\
\text { Analyzer }\end{array}$ & $\begin{array}{l}\text { Fire } \\
\text { Stats }\end{array}$ & $\begin{array}{c}\text { G0 } \\
\text { Access }\end{array}$ & $\begin{array}{c}\text { Web } \\
\text { Forensik }\end{array}$ & $\begin{array}{l}\text { AW Log } \\
\text { Analyzer }\end{array}$ & $\begin{array}{c}\text { Web Log } \\
\text { Expert }\end{array}$ & $\begin{array}{l}\text { Google } \\
\text { Analytics }\end{array}$ \\
\hline Vendor & Webalizer & Piwik Inc & $\begin{array}{l}\text { Open Web } \\
\text { Analytics }\end{array}$ & $\begin{array}{c}\text { Deep } \\
\text { Software Inc. }\end{array}$ & FirStats & GoAccess & Web Forensik & AW Stats Inc. & $\begin{array}{c}\text { Alentum } \\
\text { Software Ltd. }\end{array}$ & Google \\
\hline Type & $\begin{array}{c}\text { Web } \\
\text { Analytics }\end{array}$ & Web Analytics & $\begin{array}{c}\text { Web } \\
\text { Analytics }\end{array}$ & $\begin{array}{c}\text { Web } \\
\text { Analytics }\end{array}$ & $\begin{array}{c}\text { Web } \\
\text { StatisticSystem }\end{array}$ & $\begin{array}{l}\text { Web Log } \\
\text { Analyzer }\end{array}$ & $\begin{array}{l}\text { Web Security } \\
\text { Log Analyzer }\end{array}$ & $\begin{array}{l}\text { Web Security } \\
\text { Log Analyzer }\end{array}$ & $\begin{array}{l}\text { Web Log } \\
\text { Analyzer }\end{array}$ & $\begin{array}{c}\text { Web } \\
\text { Analytics }\end{array}$ \\
\hline $\begin{array}{l}\text { Current } \\
\text { Version }\end{array}$ & $2.23-08$ & 2.13.1 & 1.5 .7 & 6.0 & 1.6 .7 & 0.9 .1 & 0.18 & 7.4 & 8.6 & Single \\
\hline Installation & $\begin{array}{l}\text { Easy to } \\
\text { install }\end{array}$ & Easy to install & Easy to install & Easy to install & Easy to install & Easy to install & Easy to install & Easy to install & Easy to install & $\begin{array}{c}\text { No need to } \\
\text { install, } \\
\text { Google } \\
\text { Account } \\
\text { required. }\end{array}$ \\
\hline $\begin{array}{l}\text { Log File } \\
\text { Formats }\end{array}$ & $\begin{array}{l}\text { CLF, XLF, } \\
\text { ELF, FTP }\end{array}$ & $\begin{array}{l}\text { Apache, IIS, } \\
\text { Ngnix }\end{array}$ & $\begin{array}{l}\text { CLF, XLF, } \\
\text { ELF }\end{array}$ & Apache, IIS & $\begin{array}{c}\text { CLF, XLF, } \\
\text { ELF }\end{array}$ & $\begin{array}{c}\text { Apache, IIS, } \\
\text { CLF, XLF, } \\
\text { ELF }\end{array}$ & $\begin{array}{c}\text { Apache, CLF, } \\
\text { XLF, ELF }\end{array}$ & $\begin{array}{l}\text { CLF, XLF, } \\
\text { ELF }\end{array}$ & Apache, IIS & $\begin{array}{c}\text { CLF, XLF, } \\
\text { ELF }\end{array}$ \\
\hline Language & $\mathrm{C}$ & Python / Ruby & PHP & Built-in & $\begin{array}{c}\text { PHP, MySQL } \\
4.0 .17\end{array}$ & HTML & HTML / XML & Perl & Built-in & Built-in \\
\hline Available in & $\begin{array}{c}\text { Over } 30 \\
\text { languages }\end{array}$ & PHP & PHP & MS-Access & PHP & Nix Sytem & HTML / XML & $\begin{array}{c}\text { Perl/CGI/ } \\
\text { XML }\end{array}$ & Built-in & Built-in \\
\hline $\begin{array}{l}\text { Operating } \\
\text { System }\end{array}$ & $\begin{array}{l}\text { Cross- } \\
\text { plafform }\end{array}$ & Cross-plafform & $\begin{array}{l}\text { Cross- } \\
\text { plafform }\end{array}$ & Windows & Windows/ Unix & Linux & Windows & Windows & Windows & $\begin{array}{l}\text { Cross- } \\
\text { platform }\end{array}$ \\
\hline Website & $\begin{array}{c}\text { www.webaliz } \\
\text { er.org }\end{array}$ & www.piwik.org & $\begin{array}{c}\text { www.openwe } \\
\text { banalytics.co } \\
\mathrm{m}\end{array}$ & $\begin{array}{l}\text { www.deep- } \\
\text { software.com }\end{array}$ & $\begin{array}{c}\text { www.firestats.c } \\
\text { c }\end{array}$ & $\begin{array}{c}\text { www.sourcef } \\
\text { orge.net/proje } \\
\text { cts/goaccess }\end{array}$ & $\begin{array}{l}\text { www.sourcefo } \\
\text { rge.net/project } \\
\text { s/webforensik }\end{array}$ & $\begin{array}{c}\text { www.alterwin } \\
\text { d.com } \\
\text { /loganalyzer }\end{array}$ & $\begin{array}{c}\text { www.weblog } \\
\text { expert.com }\end{array}$ & $\begin{array}{c}\text { www.google } \\
\text {.com/anaytic } \\
\text { s }\end{array}$ \\
\hline Criticism & $\begin{array}{c}\text { Generated } \\
\text { statistics do } \\
\text { not } \\
\text { differentiate } \\
\text { between } \\
\text { human } \\
\text { visitors and } \\
\text { robots. }\end{array}$ & $\begin{array}{c}\text { Users are the } \\
\text { only people } \\
\text { who see their } \\
\text { own data and } \\
\text { provide limited } \\
\text { details only. }\end{array}$ & $\begin{array}{c}\text { OWA is } \\
\text { server } \\
\text { software } \\
\text { anyone can } \\
\text { install and run } \\
\text { on their own } \\
\text { host. }\end{array}$ & $\begin{array}{c}\text { Web analytics } \\
\text { solution for } \\
\text { small and } \\
\text { medium size } \\
\text { websites. }\end{array}$ & $\begin{array}{l}\text { Provides only } \\
\text { basic details. }\end{array}$ & $\begin{array}{c}\text { Provides brief } \\
\text { and beneficial } \\
\text { HTTP (web } \\
\text { server) } \\
\text { statistics } \\
\text { report for } \\
\text { Linux } \\
\text { administrators } \\
\text { only. }\end{array}$ & $\begin{array}{c}\text { Clues and } \\
\text { hints in the } \\
\text { logs are just } \\
\text { too huge to } \\
\text { browse } \\
\text { through them } \\
\text { manually. }\end{array}$ & $\begin{array}{c}\text { Might not } \\
\text { provide you } \\
\text { the tons and } \\
\text { tons of data } \\
\text { those Google } \\
\text { Analytics } \\
\text { posses in it. }\end{array}$ & $\begin{array}{c}\text { E-mail report } \\
\text { facility not } \\
\text { available in } \\
\text { lite (trial } \\
\text { version). }\end{array}$ & $\begin{array}{c}\text { Does not } \\
\text { work on } \\
\text { Raw Logs. } \\
\text { Importing } \\
\text { Raw Logs is } \\
\text { missing. }\end{array}$ \\
\hline
\end{tabular}

Webalizer tool generate statistics that is unable to distinguish the number of visits between end users and robots. Moreover, all reported statistics are greater than the actual visit. It produces extremely nonrealistic figures of visits, which are sometimes much bigger than the information generated by Javascript based web statistics, for example, Google Analytics.

In Piwik tool, service users are authorized to see their own data and provide limited details only. Open Web Analytics is server software in which users are free to install and can work on their own host. Deep Log Analyzer tool provides solution for web analytics for small and medium size websites whereas Fire Stats provides only basic details.

Go Access tool present concise and valuable HTTP (web server) statistics description for Linux administrators only. Web Forensik highlight clues and hints in the logs which are just too huge to browse through them manually. AW Log Analyzer tool might not 
provide you the tons and tons of data those Google Analytics posses in it. Web Log Expert does not provide E-mail report facility in lite (trial version). Google Analytics does not work on Raw Access Logs and importing raw logs is missing.

All the conversation associated to web log analyzer tools have been stated subject to the attributes highlighted in the Table 1 . The aim is to recognize the higher quality tools on the strength of operational and relational events which facilitate in making appropriate conclusion or result. The entire relevant result correspondent to web logs help out in recognizing the activities of user.

\subsection{Web Data Mining and Analysis: An Intelligent Perspective}

Generally, web log data of university website is generated through webalizer but it is having one major limitation. It cannot differentiate between the human user visit and robot visit. So to overcome this, Origin tool have been used for analysis of web log data which is one of the data analytic tool.

The study on university website's various web data patterns reveals the necessity to incorporate more intelligent techniques and methods for mining useful information and predicting web data analysis. Through the data analytical and graph workspace tool, we are feasible in providing relevant information related to the user access. In this research, the web data during the university's peak working time is considered from February 2014 to January 2015.

University website's main web server receives highest 4479215 hits in June 2014 and lowest 190885 hits in September 2014 in terms of monthly average. Further, it obtain highest 140685 hits in June 2014 and lowest 4032 hits in October 2014 in terms of daily average. The biggest challenge is to extract relevant information from such data sets which is too huge and chaotic. As organizations grow, there is a parallel growth of web data also.

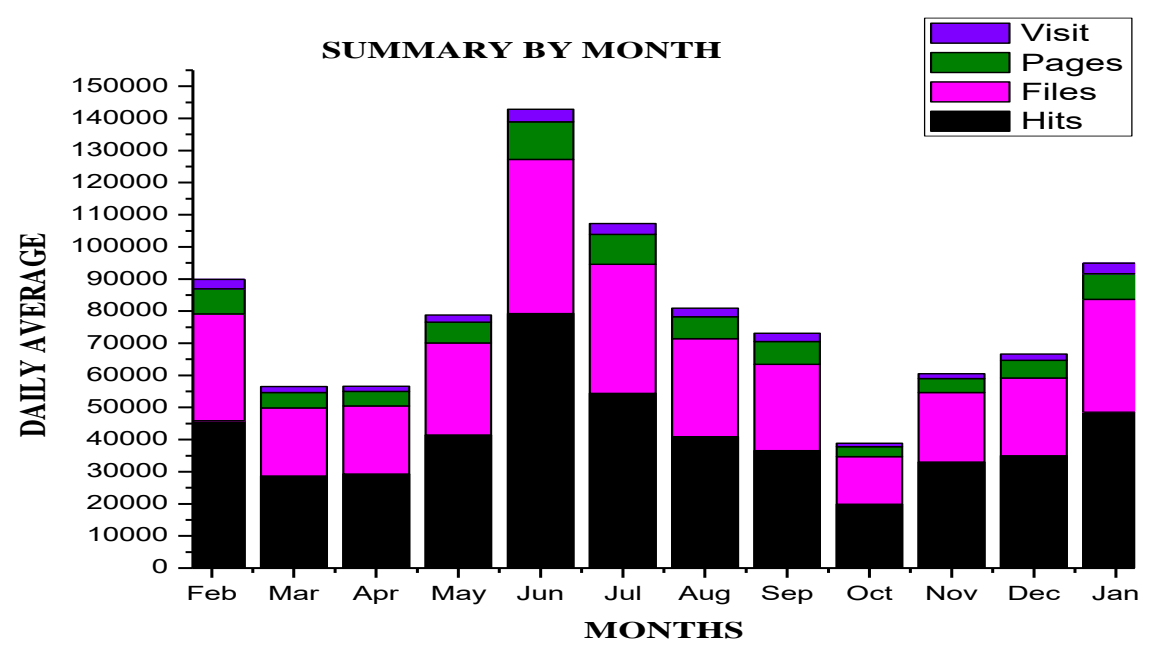

Figure 1. Daily Average Summary from February 2014 to January 2015 


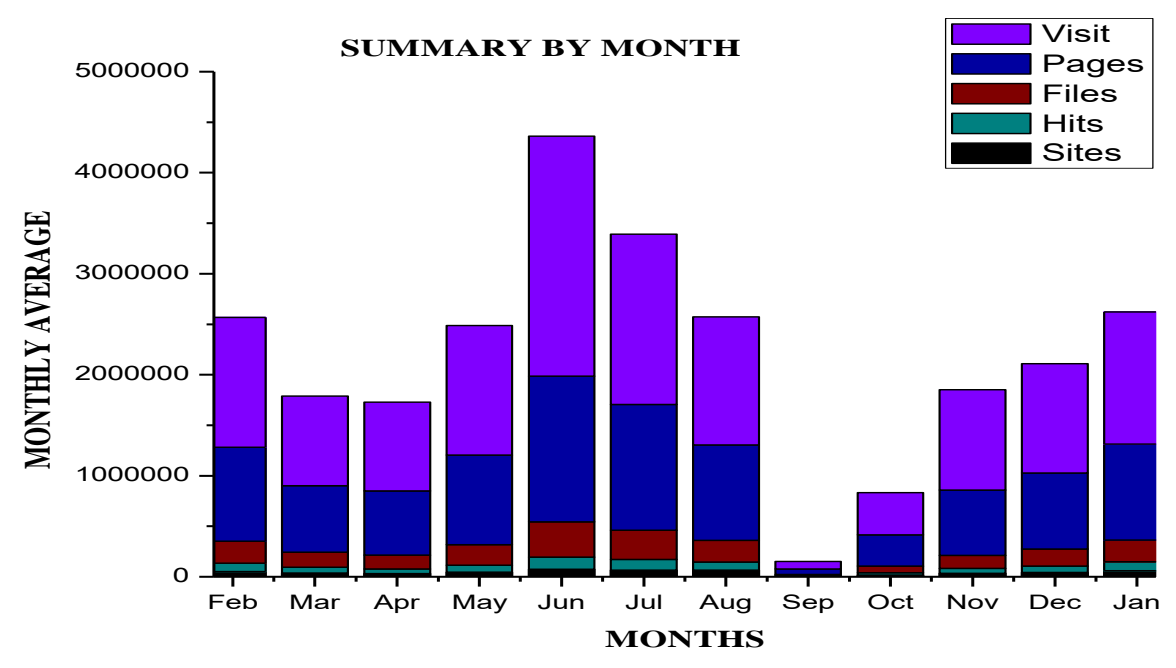

Figure 2. Monthly Average Summary from February 2014 to January 2015

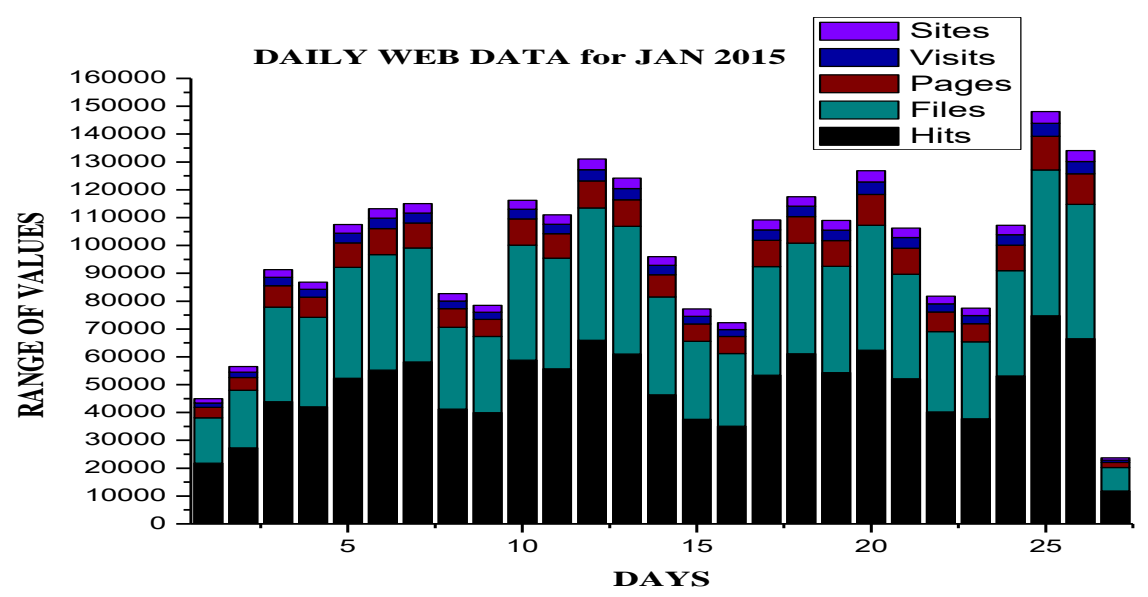

Figure 3. Daily Web Data for January 2015

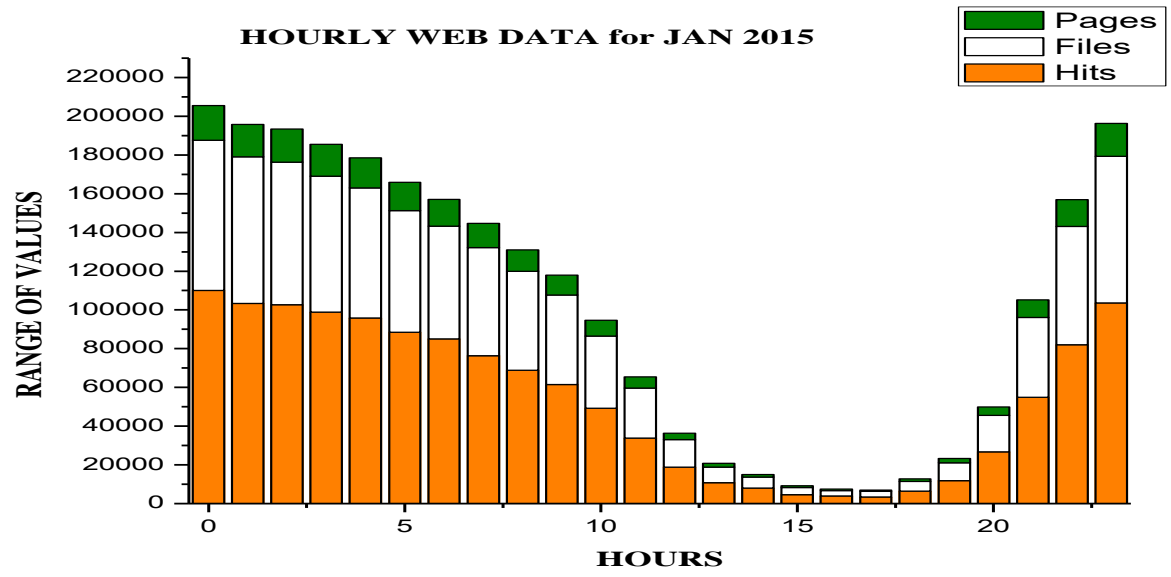

Figure 4. Hourly Web Data for January 2015

For the month of January 2015, the daily web data highlight the aggregate Hits that occur and the Files and Pages that have been visited. The highest Hits per Day were 
75934, the highest Files per Day were 56131, the highest Pages per Day were 12698, the highest visits per Day were 4635 and the highest Kbytes per Day were 22903987.

The hourly web data illuminates the number of Hits, Files and Pages. The highest Hits per hour were found to be 117977 in the month of January 2015.

\subsection{Role of Agent Communication Language in WEBMINTEL System}

WEBMINTEL (Web Mining Intelligent Agents) system is a collection of various agents. In the proposed WEBMINTEL System, Multi Agent System performs tasks such as the Registration Agent works for collecting information in cluster form. The User Agent acts as an interface between Registration Agent and Buyer as well as Seller Agent. Session Agent collects the user information which is forwarded to the Management Agent. Item Agent searches the relevant information for negotiation both from buyer as well as seller standpoints. Negotiation Agent dispatches the information generated from analysis via internet for historical database. The information is analyzed in three different ways, namely, Reject, Accept or Add to cart. If it is a Reject, then no further result or information will be delivered whereas if it is Accept, then decision or result in the form of information will be stored in history database as shown in Figure 5. Data Mining Agent performs various activities at back end such as Form Editing and managing Field Types and Result Grid.

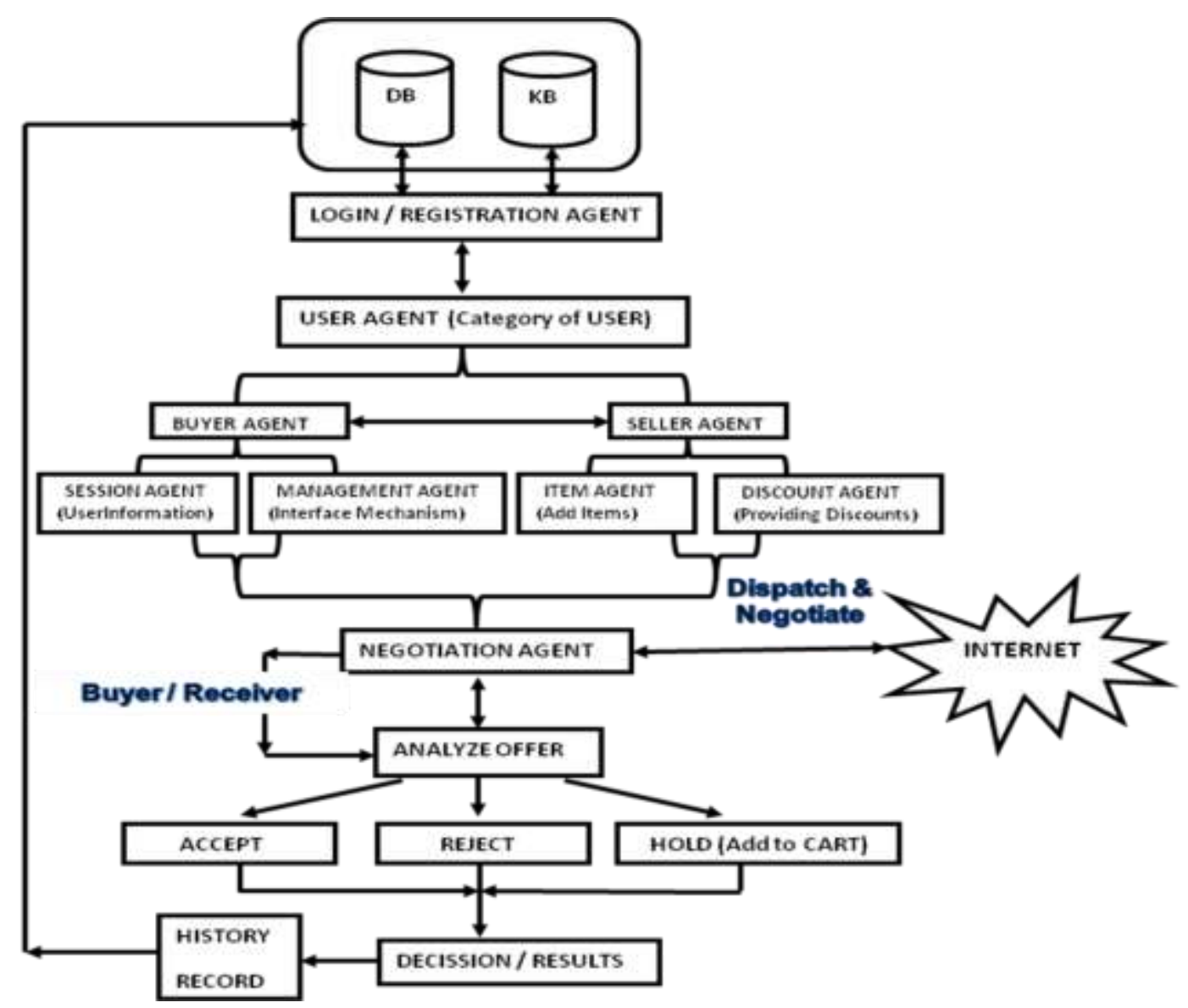

Figure 5. Web Mining Intelligent Agents (WEBMINTEL) System

In this paper we will include some of the JSP modules which will be used to accomplish the above said tasks. A segment of negotiation_agent.jsp is as follow: 


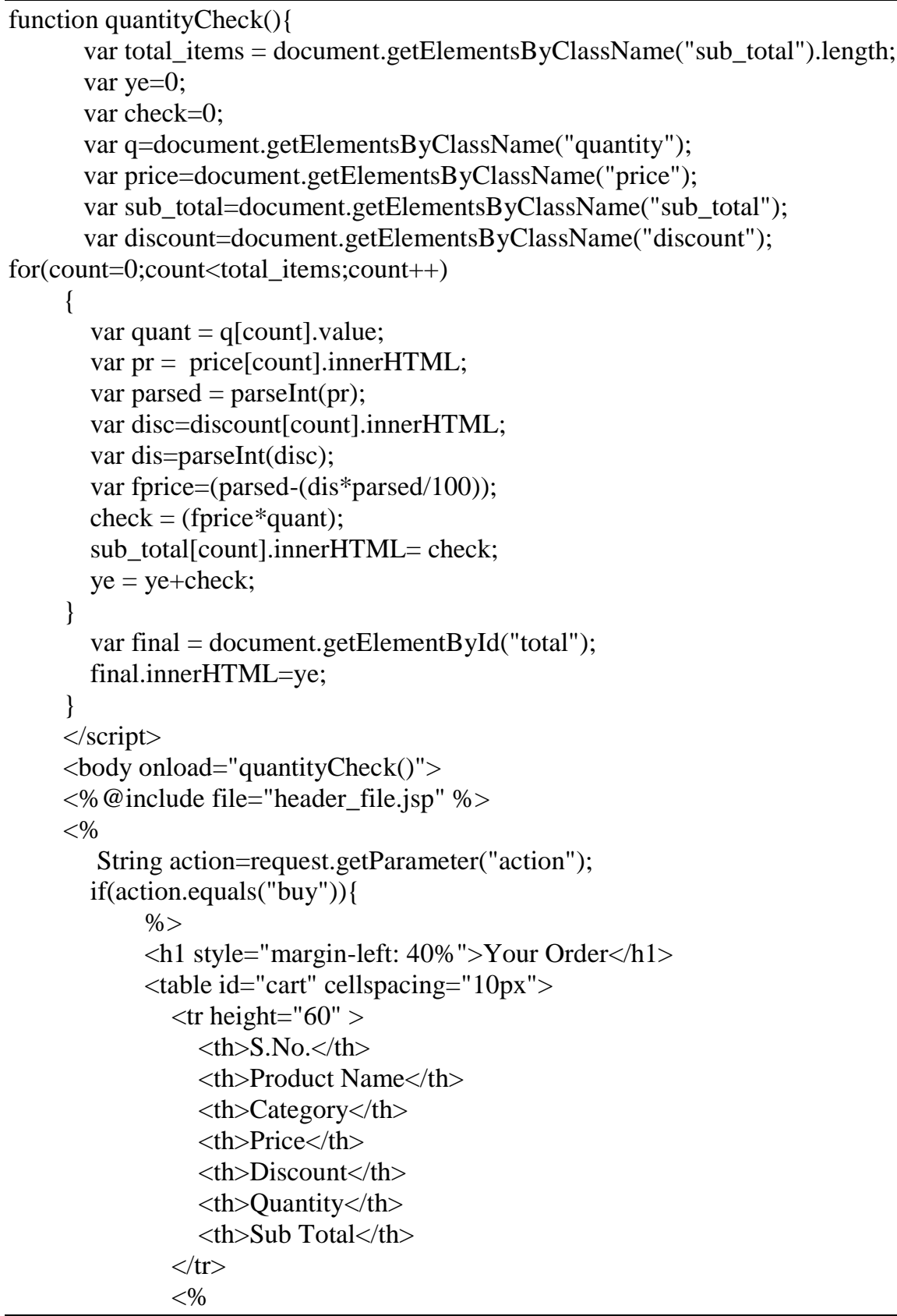

The back end interface of WEBMINTEL System worked on MySQL. Figure 6 discusses the screenshot highlighting the form editing activities done by Data Mining Agent Account Manager with the following query:

SELECT $*$ from data_mining_agent. Accounts_manager; 


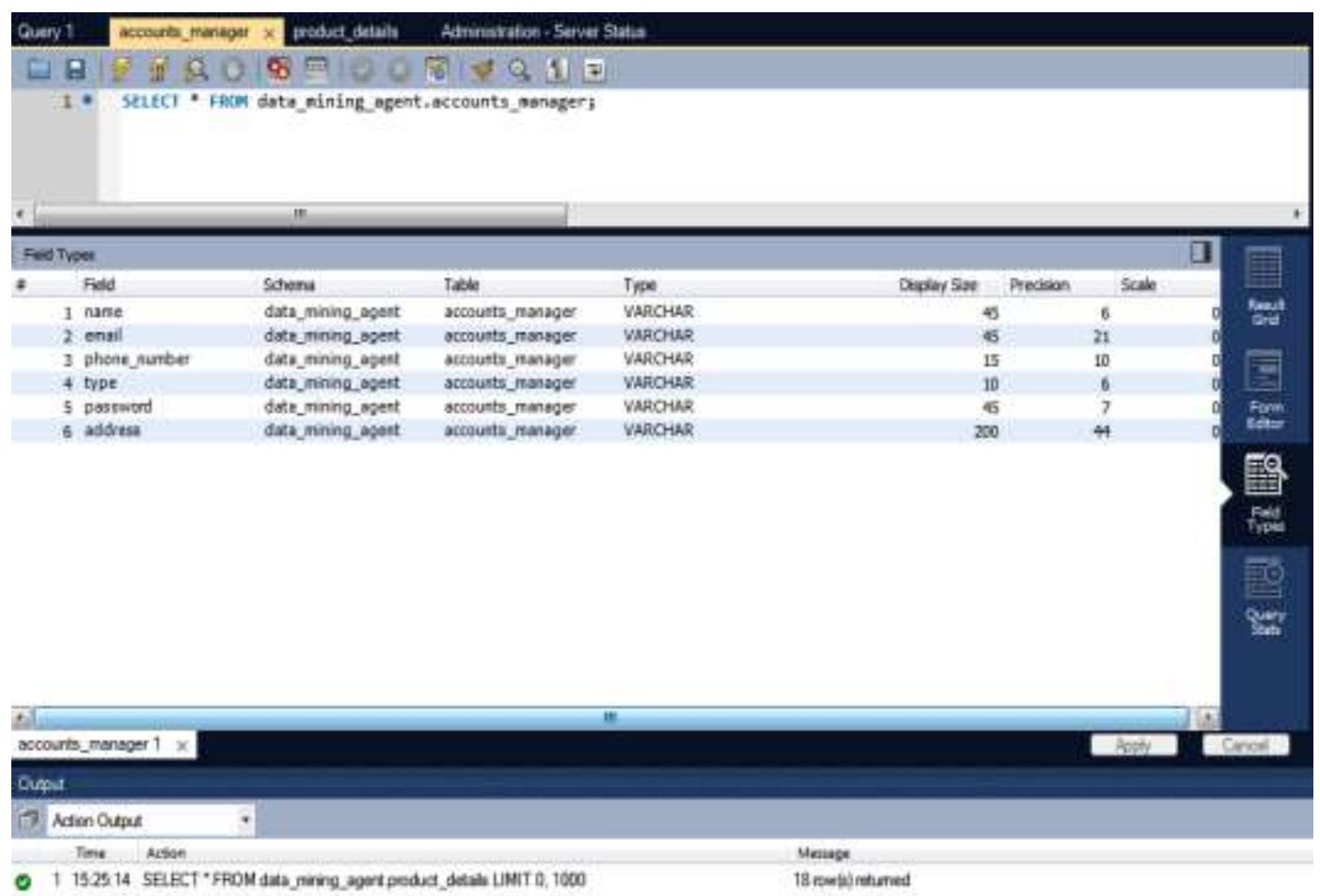

Figure 6. Data Mining Agent Accounts Manager Field Types

Table 2. Software Agents Architectures

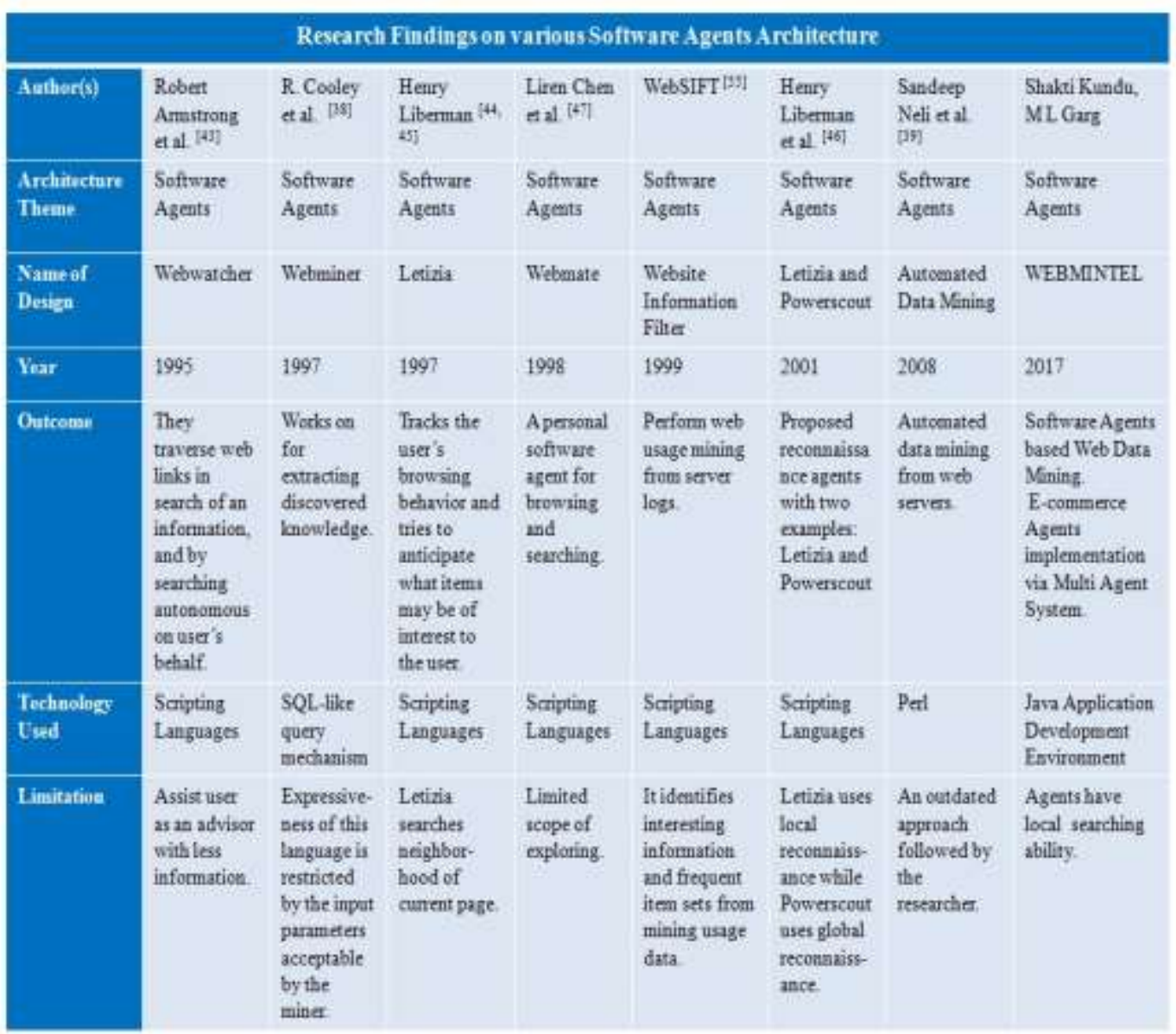




\section{Conclusions and Future Work}

A great visibility into the customer accessing website is an intelligent approach for right decision making. Web analytics with the help of automated web log analyzer tools consider web access log data as input, analyze it and generates different categories of reports. In the process of agent communication, Java Application Development Environment (JADE) has been used as an agent communication language (ACL). The proposed model of Software Agents for e-commerce application and JSP as an ACL has effectively improved the intelligence of the system. The future technology is expected to use JSP to encode information and services with meaningful structure and semantics that computers and people can readily understand.

A future research direction is to investigate an alternative approach to update the proposed system. This may be done using genetic algorithm techniques. Another future research direction could be to discover new applications of automated analyzer. The focus may be to examine the arguments an agent can use, in order to improve the analyzing outcomes.

\section{References}

[1] The IBM Agent, Available at: http://www-03.ibm.com/systems/director/downloads/agents.html. Accessed: (2016) October 09.

[2] M. Chajri and M. Fakir, "Application of data mining in e-commerce", Journal of Information Technology Research, IGI Publications, US, vol. 7, no. 4, (2014), pp. 79-91.

[3] H. Qingtian, G. Xioayan and W. Wenguo, "Study on web mining algorithm based on usage mining", Proceedings of $9^{\text {th }}$ International Conference on Computer Aided Industrial Design and Conceptual Design, IEEE Xplore, (2008), pp. 1121-1124.

[4] Q. Cen, J. Zhao and X. Zhu, "The data mining system based on multi-agent under the circumstances of e-commerce", Proceedings of $3^{\text {rd }}$ International Conference on Natural Computing (ICNC 2007) IEEE, vol. 7, (2007), pp. 34-38.

[5] Q. Tang and F. Xie, "Agent based negotiation model for e-commerce", Wireless Communications, Networking and Mobile Computing, Proceedings of WiCom 2007, International Conference, (2007), pp. 3466-3469.

[6] Y. Tang, X. Liu, Y. Huang and G. Lu, “The design of data mining system”, Theory and application of System Project, (2000), pp. 56-63.

[7] I. Tudor and L. Ionita, "Intelligent agents as data mining techniques used in academic environment", $4^{\text {th }}$ International Conference on Virtual Learning ICVL, (2009), pp. 380-384.

[8] L. Hanyang, G. Jinling and J. Wenli, "Research on data mining in e-business websites", Proceedings of International Conference on Computer Science and Software Engineering, IEEE Xplore, vol. 4, (2008), pp. 336-339.

[9] A. T. Siddiqui and S. Aljahdali, "Web mining techniques in e-commerce applications", International Journal of Computer Applications, vol. 69, no. 8, (2013), pp. 39-43.

[10] I. Dzitac and I. Moisil, "Advanced AI techniques for web mining", Proceeding of the 10th WSEAS International conference on Mathematical methods, Computational techniques and Intelligent Systems (MAMECTIS'08), (2008), pp. 343-346.

[11] J. Srivastava, R. Cooley, M. Deshpande and P. N. Tan, "Web usage mining: Discovery and applications of usage patterns from web data", Proceedings of SIGKDD Explorations, vol. 1(2), (2000), pp. 12-23.

[12] R. Cooley, B. Mobasher and J. Srivastava, "Web mining: Information and pattern discovery on the world wide web", Proceedings of $9^{\text {th }}$ International Conference on Tools with Artificial Intelligence, IEEE Xplore, (1997), pp. 558-567.

[13] S. Neeli, K. Govindasamy, B. M. Wilamowski and A. Malinowski, "Automated data mining from web servers using perl script", Proceedings of $12^{\text {th }}$ International Conference on Intelligent Engineering Systems, Miami, Florida, (2008), pp. 191-196.

[14] L. Chen and K. Sycara, "WebMate : A personal agent for browsing and searching", Proceedings of the second International Conference on Autonomous Agents, (1998), pp. 132-139.

[15] R. Armstrong, D. Freitag, T. Joachims and T. Mitchell, "WebWatcher: A learning apprentice for the world wide web", AAAI Spring Symposium on Information Gathering, Stanford, CA, Available at: http://www.cs.cmu.edu/afs/cs/project/theo-6/web-agent/www/project-home.html, (1995).

[16] H. Liberman and Letizia, "An agent that assists web browsing", Proceedings of the 14th International Joint Conference on Artificial intelligence, vol. 1, (1995), pp. 924-929.

[17] H. Liberman, "Autonomous interface agents", Proceedings of the ACM SIGCHI Conference on Human Factors in Computing Systems, (1997), pp. 67-74. 
[18] H. Liberman, C. Fry and L. Weitzman, "Exploring the web with reconnaissance agents", Communication of the ACM, vol. 44, no. 8, (2001), pp. 69-75.

[19] R. Cooley, P. Tan and J. Srivastava, "Discovery of interesting usage patterns from web data", Proceedings of WEBKDD '99 Revised Papers from the International Workshop on Web Usage Analysis and User Profiling, (1999), pp.163-182.

[20] Top 10 Web Log Analyzers, Available at: http://www.valencynetworks.com/articles/top-10-web-loganalyzers.html. Accessed: (2016) November 19.

[21] Q. Tang and F. Xie, "Agent based negotiation model for e-commerce", Proceedings of International Conference of Wireless Communications, Networking and Mobile Computing, (2007), pp. 3466-3469.

[22] Agrawal and Srikant, "Popular algorithm for mining frequent itemsets is Apriori", Proceedings of 20th International Conference on Very Large Data Bases, Santiago de Chile, Chile, (1994), pp. 487-499.

[23] S. Arumugaperumal, "Integrating e-commerce and CRM with data mining: A new era", Journal of Internet Banking and Commerce, vol. 10, no. 3, (2005), pp. 2-9.

[24] S. Ansari, R. Kohavi, L. Mason and Z. Zheng, "Integrating e-commerce and data mining: Architecture and challenges", Proceedings of IEEE International Conference on Data Mining, (2001), pp. 27-34.

[25] D. M. Auguste, "Customer service in e-business", Proceedings of IEEE Internet Computing, vol. 5, no $.5,(2001)$, pp. 90-91.

\section{Authors}

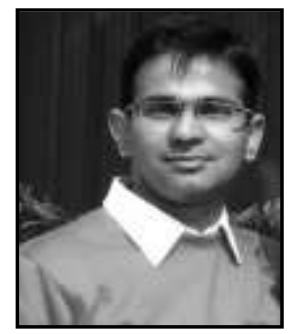

Shakti Kundu, he received his M.Tech. in Computer Science \& Engineering from Guru Jambheshwar University of Science \& Technology, Hisar, Haryana, India in 2010, M.Phil. in Computer Science from Chaudhary Devi Lal University, Sirsa, Haryana, India in 2008, M.C.A. from Kurukshetra University Kurukshetra, Haryana, India in 2006. Presently he is pursuing his Ph.D in CSE from DIT University, Dehradun, India. The author current research interests are Web Data Mining, Knowledge Management and Web Testing. He is life member of CSI, ISTE, IAENG, AIRCC and IAEME.

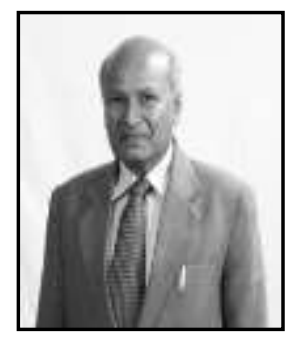

M L Garg, he is presently Professor, Department of Computer Science \& Engineering at DIT University, Dehradun, India, has obtained his Ph.D degree in Computer Science \& Engineering from Thapar Institute of Engineering \& Technology (Deemed University), Patiala, India with collaborative research work at IIT Delhi, in the year 1992. His area of research includes Fuzzy Logic Genetic Algorithms \& Knowledge Representation and Reasoning. $\mathrm{He}$ is on the Editorial Board of the International Journal of Cloud Computing and Super Computing (IJCS), Canada. 